\title{
Magnetic Viscosity of Sr-Na-Zn W-Type Hexagonal Ferrite Magnets
}

\author{
H. Nishio and H. Yamamoto*
}

Materials Research Center, TDK Corporation, 570-2 Aza-Matsugashita, Minami-Hatori, Narita 286, Japan

* School of Science and Technology, Meiji University, 1-1-1 Higashimita, Tama-ku, Kawasaki 214, Japan

\begin{abstract}
The temperature dependence of the magnetic viscosity coefficient (Sv), the activation volume (v), and the anisotropy field $\left(\mathrm{H}_{A}\right)$ were examined for $\mathrm{Sr}-\mathrm{Na}-\mathrm{Zn}$ W-type hexagonal ferrite magnet from 77 to $623 \mathrm{~K}$. Samples with different coercive forces (HcJ) were prepared, and the dependence of $\mathrm{Sv}$ and $\mathrm{v}$ on $\mathrm{HcJ}$ was studied at $300 \mathrm{~K}$. The results show that the temperature dependence of Sv is the same as that of $\mathrm{HCJ}_{\mathrm{J}}$. The value of $v$ is inversely proportional to $H_{A}$. The logarithm of $S v$ is proportional to $\ln H c J$ and $H c J$ is proportional to $\mathrm{v}^{-2.1}$, as in the case of $\mathrm{Sm}_{2} \mathrm{Fe}_{17} \mathrm{~N}_{\mathrm{X}}$ and $\mathrm{SrM}$ particles used in magnets and BaM fine particles used for high density recording media. They are considered to have a similar coercive force mechanism.
\end{abstract}

\section{INTRODUCTION}

In recent years, there has been a growing interest in W-type hexagonal ferrite which has a saturation magnetization (Js) about $10 \%$ greater than that of M-type hexagonal ferrite. Many reports on the magnetism of W-type Hexagonal ferrites have been published[1,2], though studies on their magnetic viscosity are particularly few. The magnetic viscosity in permanent magnets belongs to the Jordan-type aftereffect phenomenon and is caused by thermal fluctuations [3,4]. It is known to depend on the magnetic viscosity coefficient (Sv), the irreversible susceptibility (Xirr) and the logarithmic time (In t) [3-5]. When the change in magnetization from time $t_{1}$ to $t_{2}(\Delta J)$ is considered, Sv can be expressed using the following equation[3-5]:

$$
\mathrm{Sv}=\Delta \mathrm{J} / \mathrm{Xirr}\left(\ln \mathrm{t}_{1}-\ln \mathrm{t}_{2}\right)=\mathrm{kT} /(\partial \mathrm{E} / \partial \mathrm{H})_{\mathrm{T}}=\mathrm{kT} / \mathrm{v} \mathrm{Js}
$$

where $\mathrm{k}$ is the Boltzman constant, $\mathrm{E}$ is the activation energy, $\mathrm{v}$ is the activation volume and $\mathrm{H}$ is the magnetic field. This paper reports on studies of the temperature dependence of $\mathrm{Sv}$ and the anisotropy field $\left(\mathrm{H}_{\mathrm{A}}\right)$ for a $\mathrm{Sr}-\mathrm{Na}-\mathrm{Zn} \mathrm{W}$-type hexagonal ferrite in the temperature range from 77 to $623 \mathrm{~K}$. Also, the relationships between the coercive force ( $\mathrm{HcJ}$ ) and both Sv and $\mathrm{v}$ were investigated at $300 \mathrm{~K}$.

\section{EXPERIMENTAL}

Sr-Zn W-type hexagonal ferrite was investigated with $1.33 \mathrm{wt} \% \mathrm{Na}_{2} \mathrm{O}$ and $0.67 \mathrm{wt} \% \mathrm{SrO}$, which were added after semisintering treatment. Table 1 shows sintering conditions, grain size (D) and the magnetic properties of Sr-Na-Zn W-type hexagonal ferrite magnets. These samples were spherical with diameters of $4 \mathrm{~mm}$. After the application of $1.6 \mathrm{MA} / \mathrm{m}$, the samples were subjected to a constant external field (Hex) for $1000 \mathrm{~s}$ and $\Delta \mathrm{J}$ was measured using a vibrating sample magnetometer (VSM). The apparent reversible susceptibility (Xrev) and the total differential susceptibility (X'tot), obtained by differentiating the demagnetizing curve with respect to Hex, were also measured using a VSM. X'irr can be expressed as X'tot - X'rev, where the prime indicates the values before correcting for the demagnetizing field. Corrections were made for the demagnetizing field using a demagnetizing factor of $\mathrm{N}=1 / 3$. The uniaxial anisotropy constant $\left(\mathrm{K}_{\mathrm{A}}\right)$ is obtained from unsaturated torque curves. For the torque magnetometer used, fields were available in the range of 0.8 to $2 \mathrm{MA} / \mathrm{m}$. The coefficient of the $\sin 2 \theta$ term $w$ as extrapolated to infinite $\mathrm{H}$ by plotting against $1 / \mathrm{H}$. The uniaxial anisotropy constants and the anisotropy fields are related by $\mathrm{H}_{\mathrm{A}}=2 \mathrm{~K}_{\mathrm{A}} / \mathrm{J} \mathrm{s}$.

\begin{tabular}{|c|c|c|c|c|c|c|}
\hline Sample & Sintering conditions & $\mathrm{D}(u \mathrm{~m})$ & $J s(T)$ & $\mathrm{Br}(\mathrm{T})$ & $\mathrm{HcJ}(\mathrm{kA} / \mathrm{m})$ & (BH)max $\left(\mathrm{kJ} / \mathrm{m}^{3}\right)$ \\
\hline $\mathrm{A}$ & $1225^{\circ} \mathrm{C} \times 0.5 \mathrm{~h}$ & $0.5-1.5$ & 0.407 & 0.335 & 138 & 19.3 \\
\hline B & $1275^{\circ} \mathrm{C} \times 1.0 \mathrm{~h}$ & $1.1-2.0$ & 0.407 & 0.349 & 82 & 15.3 \\
\hline $\mathrm{C}$ & $1300^{\circ} \mathrm{C} \times 0.5 \mathrm{~h}$ & $1.8-4.0$ & 0.456 & 0.395 & 36 & 5.4 \\
\hline $\mathrm{D}$ & $1300^{\circ} \mathrm{C} \times 1.0 \mathrm{~h}$ & -40 & 0.456 & 0.414 & 18 & 2.4 \\
\hline$E$ & $1300^{\circ} \mathrm{C} \times 2.0 \mathrm{~h}$ & -60 & 0.456 & 0.417 & 14 & 1.2 \\
\hline
\end{tabular}




\section{RESULTS AND DISCUSSION}

Similar curvatures of the magnetic field dependencies of $\Delta \mathrm{J}^{\prime} /\left(\ln \mathrm{t}_{2}-\ln \mathrm{t}_{2}\right)$ and X'irr were observed for Sample $A$ and these had maximum values around the Hc $J$ point for each temperature. Figure 1 shows the magnetic field dependence of Sv for Sample A obtained from Eq.(1), using the values of $\Delta \mathrm{J}^{\prime} /\left(\ln \mathrm{t}_{1} \cdot \ln \mathrm{t}_{2}\right)$ and X'irr. The range in which Sv stays constant with $\mathrm{Hex}$ is very wide at each temperature. For Sample A, Js and $\mathrm{K}_{\mathrm{A}}$ both decreased as temperature increased. The temperature dependence of $\mathrm{Sv}$ and $\mathrm{H}_{\mathrm{c} J}$ is shown in Figure 2 for Sample A. The temperature dependence of $\mathrm{Sv}$ is the same as that of $\mathrm{HcJ}_{\mathrm{J}}$. Sv and $\mathrm{HcJ}$ increase with the increase in the temperature between $77 \mathrm{~K}$ and $500 \mathrm{~K}$, as in the case of $\mathrm{SrM}$ and BaM magnets[6]. The values of Sv and HcJ are maximized near $520 \mathrm{~K}$ and decrease suddenly after that. The temperature dependence of the anisotropy field $\left(\mathrm{H}_{\mathrm{A}}\right)$ obtained using the values of $\mathrm{K}_{\mathrm{A}}$ is shown in Figure 3 along with the activation volume ( $v$ ) calculated from $\mathrm{Sv}$. The value of $\mathrm{v}$ is inversely proportional to $\mathrm{H}_{\mathrm{A}}$ in the temperature range from $77 \mathrm{~K}$ to $623 \mathrm{~K}$. Figure 4 shows the dependence of $\mathrm{Sv}$ and $\mathrm{v}$ on $\mathrm{HeJ}$ at $300 \mathrm{~K}$ for $\mathrm{Sr}-\mathrm{Na}-\mathrm{Zn} \mathrm{W}$-type hexagonal ferrite samples $\mathrm{A}, \mathrm{B}$, C, D and $\mathrm{E}$. The logarithm of Svis proportional to the logarithm of $\mathrm{H}_{\mathrm{c} J}$ and $\mathrm{H}_{\mathrm{c} J}$ is proportional to $\mathrm{v}^{-2.1}$, as in the case of $\mathrm{Sm}_{2} \mathrm{Fe}_{17} \mathrm{~N}_{x}$ and SrM particles used in permanent magnets and BaM fine particles used for high density magnetic recording media[7-9]. It is believed that they have a similar coercive force mechanism.

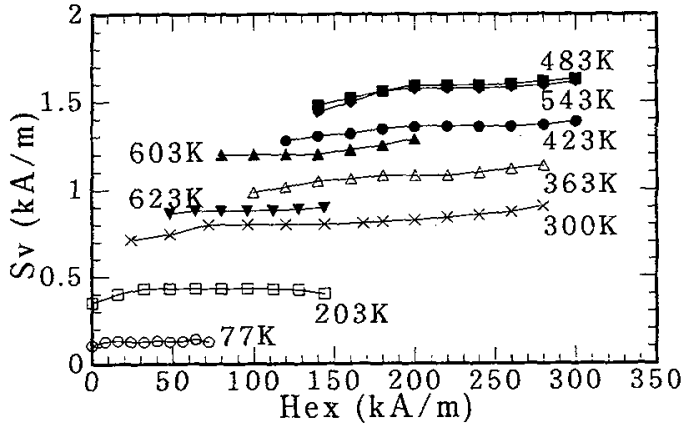

Figure 1. External field dependence of the magnetic viscosity coefficient $\mathrm{Sv}$ for Sample $\mathrm{A}$ at various temperature.

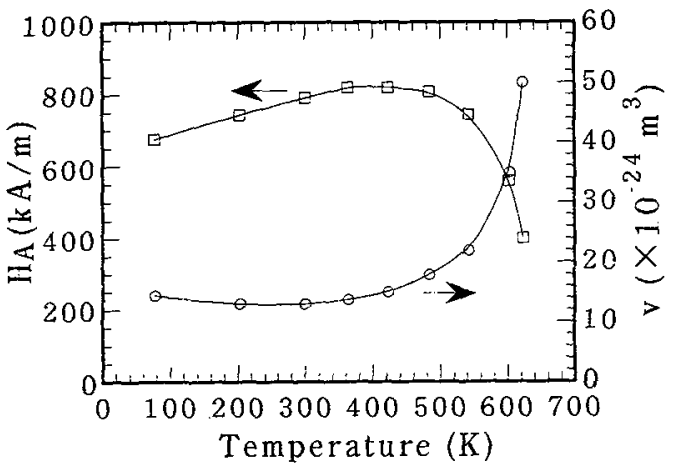

Figure 3. Temperature dependence of the anisotropy field $H_{A}$ and the activation volume $v$ for Sample $A$ in the temperature range between 77 and $623 \mathrm{~K}$.

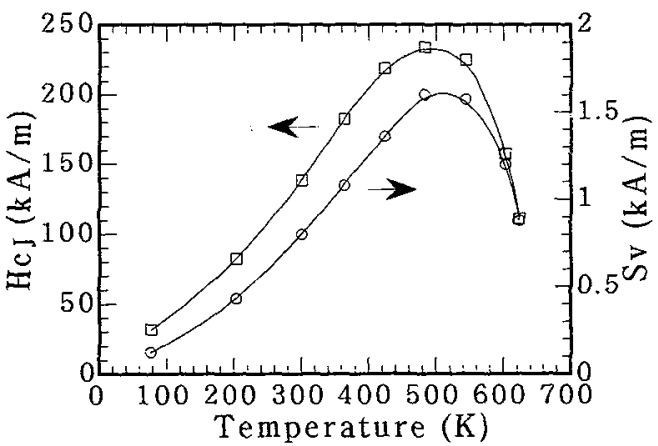

Figure 2. Temperature dependence of coercive force $\mathrm{HCJ}$ and the magnetic viscosity coefficient $\mathrm{Sv}$ for Sample $\mathrm{A}$ in the temperature range between 77 and $623 \mathrm{~K}$.

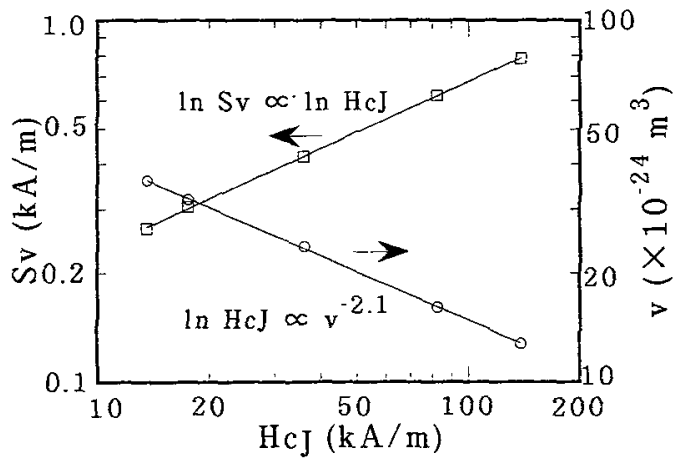

Figure 4. Plots of the magnetic viscosity coefficient $\mathrm{Sv}$ and the activation volume $v$ against coercive force $\mathrm{HcJ}$ for $\mathrm{Sr}-\mathrm{Na}-\mathrm{Zn} \mathrm{W}$-type hexagonal ferrites.

\section{References}

[1] Collomb A. and Mignot J.P., J. Magn. Magn. Mat., 69 (1987) 330-336.

[2] Collomb A., Litsardakis G., Samaras D. and Pannetier J., J. Magn. Magn. Mat., 78 (1989) 219-225.

[3] Street R. and Woolley J.C., Proc. Phys. Soc., A62 (1949) 562-572.

[4] Neel L., J. Phys. Rad., 12 (1951) 339-351.

[5] Gaunt P., Philos. Mag., 34 (1976) $775-780$.

[6] Nishio H., Taguchi H. and Yamamoto H., "Magnetic aftereffects of anisotropy M-type hexagonal ferrite magnets", Proc. 6th Int. Conf. on Ferrite (ICF6), Tokyo 29 September - 02 October 1992, pp. 1129-1132.

[7] Nishio H., Ishizaka C., Hidaka T., Fukuno A. and Yoneyama T., "Magnetic viscosity in powder and compacted powder magnets of $\mathrm{Sm}_{2} \mathrm{Fe}_{17} \mathrm{~N}_{x}$, Proc. 8 th Int. Symp. on Magnetic Anisotropy and Coercivity in $\mathrm{RE}$ TM Alloys, Birmingham 15 September 1994, pp. 423-435.

[8] Nishio H., Taguchi H., Hirata F. and Takeishi T., IEEE Trans. Magn., 29 (1993) 2637-2639.

[9] Nishio H., J. Magn. Soc. Jpn., 13 S1, (1989) 697-702. 